\title{
Estudio de dieta en poblaciones arqueológicas del centro de Argentina a través del análisis de microrrestos vegetales e isótopos estables
}

\author{
Aldana Tavarone, María de los Milagros Colobig y Mariana Fabra \\ Recibido 21 de julio 2020 Aceptado 22 de octubre 2020
}

\begin{abstract}
RESUMEN
Se presentan los resultados obtenidos a partir del análisis de isótopos estables $\left(\delta^{13} \mathrm{C}_{\text {col }}\right.$ y $\left.\delta^{15} \mathrm{~N}\right)$ y de los microrrestos vegetales hallados en el cálculo dental de 43 individuos adultos (28 masculinos - 15 femeninos) y un individuo juvenil (masculino), datados por AMS entre $387 \pm 41$ y $4058 \pm 89{ }^{14} \mathrm{C}$ años $\mathrm{AP}$, con el objetivo de abordar, desde una perspectiva bioarqueológica, el estudio de la dieta de los grupos humanos que ocuparon la región central del país. Los individuos provienen de 22 sitios arqueológicos, ubicados en dos regiones geográficas diferentes de la provincia de Córdoba: Sierras y Llanuras. Las prevalencias se calcularon considerando sexo, cronología y procedencia geográfica de cada individuo. Los resultados sugieren el consumo principalmente de plantas silvestres con patrón fotosintético $\mathrm{C}_{3^{\prime}}$ tales como Prosopis sp., Geoffroea decorticans y Trithrinax campestris a lo largo de todo el Holoceno tardío, y la incorporación de recursos vegetales cultivados de tipo $\mathrm{C}_{4}$, como Zea mays, y $\mathrm{C}_{3}$ como Phaseolus sp. a partir de los $1192 \pm 40{ }^{14} \mathrm{C}$ años AP en la región Llanuras, con la posterior incorporación de Cucurbita sp. y Solanum tuberosum, ambos con patrón fotosintético $\mathrm{C}_{3^{\prime}}$, hacia los $954 \pm 85{ }^{14} \mathrm{C}$ años AP exclusivamente en Sierras.
\end{abstract}

Palabras clave: Silicofitolitos; Granos de almidón; Tártaro dental, $\delta^{13} \mathrm{C}_{\mathrm{col}}$ y $\delta^{15} \mathrm{~N}$; Holoceno tardío.

\begin{abstract}
A STUDY OF DIET IN ARCHAEOLOGICAL POPULATIONS OF CENTRAL ARGENTINA THROUGH THE ANALYSIS OF VEGETABLE MICROREMAINS AND ISOTOPIC EVIDENCE. In this paper, results of the analysis of stable isotopes $\left(\delta^{13} \mathrm{C}_{\text {col }}\right.$ and $\left.\delta^{15} \mathrm{~N}\right)$ and vegetable microremains found in the dental calculus of 43 adult individuals (28 male, 15 female) and one juvenile (male), dated by AMS to between $387 \pm 41$ and $4058 \pm 89{ }^{14} \mathrm{C}$ years $\mathrm{BP}$, are presented in order to conduct a bioarchaeological study of the diet of the human groups that occupied the central region of Argentina. The individuals come from 22 archaeological sites located in two different geographical regions of Córdoba Province, the Sierras and Llanuras. The prevalence rates were calculated on the basis of sex, chronology, and geographic origin of each individual. The results suggest the consumption mainly of wild plants with a $\mathrm{C}_{3}$ photosynthetic pattern, such as Prosopis sp., Geoffroea decorticans and Trithrinax campestris, during the entire Late Holocene and the incorporation of cultivated plant resources of type $C_{4}$, such as Zea mays, and $C_{3}$, such as Phaseolus sp., from $1192 \pm 40$ ${ }^{14} \mathrm{C}$ years BP in the Llanuras region, with the later incorporation of Cucurbita sp. and Solanum tuberosum, both with a $\mathrm{C}_{3}$ photosynthetic pattern, towards $954 \pm 85{ }^{14} \mathrm{C}$ years BP exclusively in the Sierras.
\end{abstract}

Keywords: Silicophytoliths; Starch grains; Dental calculus; $\delta^{13} \mathrm{C}_{\text {col }}$ and $\delta^{15} \mathrm{~N}$ ratios; Late Holocene.

Aldana Tavarone. Instituto de Antropología de Córdoba-Consejo Nacional de Investigaciones Científicas y Técnicas (IDACOR-CONICET). Facultad de Filosofía y Humanidades, Universidad Nacional de Córdoba (UNC), Argentina. Av. Hipólito Yrigoyen 174, P 5000 Córdoba, Argentina. E-mail: aldyt@hotmail.com

María de los Milagros Colobig. Laboratorio de Arqueología, Centro de Investigación Científica y de Transferencia Tecnológica a la Producción (CICYTTP-CONICET- Prov. Entre Ríos - UADER). España I49, Diamante, E3I05BWA Entre Ríos, Argentina. E-mail: milagroscolobig@gmail.com

Mariana Fabra. Instituto de Antropología de Córdoba (IDACOR-CONICET). Facultad de Filosofía y Humanidades, Universidad Nacional de Córdoba (UNC), Argentina. Av. Hipólito Yrigoyen 174, P 5000 Córdoba, Argentina. E-mail: marianafabra@gmail.com

Intersecciones en Antropología 21(2), julio-diciembre: 213-227. 2020. ISSN-e 1850-373X

https://doi.org/10.37176/iea.21.2.2020.556

Facultad de Ciencias Sociales - UNICEN - Argentina 


\section{INTRODUCCIÓN}

El análisis de los macro y microrrestos botánicos en contextos arqueológicos se ha convertido en un instrumento fundamental para la reconstrucción de los modos de vida y patrones de subsistencia de los grupos humanos en el pasado, a partir del cual se logran identificar las principales especies que fueron consumidas, utilizadas y cultivadas por las distintas poblaciones prehispánicas (Recalde y López, 2017; Costa Angrizani et al., 2019; Prieto-Olavarría et al., 2019). A su vez, el estudio de isótopos estables $\left(\delta^{13} C_{\text {col }}\right.$ y $\delta^{15} \mathrm{~N}$ ) constituye una herramienta independiente $y$ complementaria para inferir aquellos recursos potencialmente ingeridos y su importancia relativa en la dieta (Lee-Thorp, 2008; Makarewicz y Sealy, 2015; Fabra y González, 2019). La combinación de ambas líneas de investigación permite estimar con mayor precisión la variedad de alimentos seleccionados, al otorgar evidencia directa sobre el consumo de plantas por parte de las poblaciones que ocuparon la región central del país los últimos 4000 años.

En la provincia de Córdoba, la evidencia aportada desde la arqueobotánica y la etnohistoria sugiere que la recolección se habría basado principalmente en frutos silvestres de tipo $\mathrm{C}_{3}$ tales como el algarrobo (Prosopis sp.), chañar (Geoffroea decorticans) y piquillín (Condalia microphylla) (López, 2017; Recalde y López, 2017), como así también de frutos del tala (Celtis ehrenbergiana), molle (Lithraea molleoides), mistol (Ziziphus mistol) y aguaribay (Schinus areira) (Silva et al., 2001). Por otro lado, hacia los 3000 años AP se habría incorporado en la región serrana el maíz (Zea mays), una de las pocas plantas cultivadas con un patrón fotosintético de tipo $\mathrm{C}_{4}$; y posteriormente, la calabaza o zapallo (Cucurbita sp.), porotos (Phaseolus sp.), quinua (Chenopodium quinoa) y papa (Solanum tuberosum) de tipo $\mathrm{C}_{3^{\prime}}$, hacia los $1028 \pm 40$ años AP (Pastor et al., 2012-2014; López et al., 2015; Medina et al., 2016); mientras que en la región Llanuras, la cronología de los hallazgos indica una primera incorporación de porotos (Phaseolus sp.) y maíz (Zea mays) alrededor de los 1200 años AP, seguidos por el zapallo o calabaza (Cucurbita sp.) aproximadamente a los 1000 años AP (Tavarone et al., 2019).

A su vez, la alternancia de variaciones climáticas significativas a lo largo del Holoceno, particularmente en el medio, con condiciones áridas y frías que tuvieron un reverso hacia húmedas y cálidas hacia comienzos del primer milenio de la era (Piovano et al., 2009), seguramente tuvo su correlato en la oferta ambiental disponible en la región, así como en los recursos potencialmente seleccionados por las poblaciones asentadas en ambientes serranos y llanos, vinculados a ríos y lagunas.

En este contexto, el objetivo del presente trabajo consiste en contribuir a la problemática de las prácticas de consumo de las principales plantas que fueron seleccionadas por estos grupos humanos a lo largo del Holoceno tardío en ambas regiones geográficas de la provincia de Córdoba, combinando la información obtenida a partir de los microrrestos vegetales contenidos en el cálculo dental (silicofitolitos y granos de almidón) con la de los isótopos estables de carbono y nitrógeno $\left(\delta^{13} \mathrm{C}_{\text {col }}\right.$ y $\left.\delta^{15} \mathrm{~N}\right)$.

\section{MATERIALES Y MÉTODOS}

Se seleccionaron aquellos individuos que contaran con información contextual y/o cronológica relativa y absoluta, que permitiera situarlos en un marco temporal y espacial específico (Tabla 1). Durante la extracción del cálculo dental y análisis de microrrestos vegetales se siguieron las pautas metodológicas y bibliográficas presentadas en Tavarone et al. (2018 y 2019). Particularmente para la identificación de los elementos silíceos, se siguió la clasificación propuesta por International Code for Phytolith Nomenclature (ICPN 2.0, 2019); asimismo, cuando la forma no se establece en la codificación, se cita la bibliografía de referencia para cada morfología, mientras que para la descripción de los granos de almidón se siguieron las pautas clasificatorias del International Code for Starch Nomenclature (ICSN, 2011) y bibliografía con material de referencia.

Las determinaciones de los valores isotópicos de $\delta^{13} C_{\text {col }}$ y $\delta^{15} \mathrm{~N}$ fueron realizadas sobre el colágeno de tejido óseo y dental de 33 de los 44 individuos analizados (Tabla 1), como parte de los análisis radiocarbónicos. Se trabajó con tres laboratorios: 1) Escuela de Graduados en Ciencias de Frontera, Universidad de Tokio (código de laboratorio MTC); 2) KCCAMS de la Universidad de Irvine, California (código de laboratorio $\mathrm{UCl}$ ); 3) Universidad de Arizona (código de laboratorio AA). Especificaciones acerca de las metodologías de extracción y análisis fueron presentadas por Fabra y González (2019). Finalmente, aplicamos un análisis de varianza (ANOVA) para evaluar la significancia estadística de las diferencias observadas; en nuestro caso, el efecto de un factor (región, sexo y cronología) sobre el conjunto de datos de $\delta^{13} \mathrm{C}_{\text {col }}$ y $\delta^{15} \mathrm{~N}$. 
Estudio de dieta en poblaciones arqueológicas del centro de Argentina a través del análisis de... Intersecciones en Antropología 21(2), julio-diciembre. 2020. ISSN-e 1850-373X

\begin{tabular}{|c|c|c|c|c|c|c|c|c|c|c|c|c|c|}
\hline : & Sitio & Lat & Long & $\begin{array}{l}\text { Indivi- } \\
\text { duo }\end{array}$ & Sexo & $\begin{array}{c}\text { Edad } \\
\text { promedio }\end{array}$ & $\begin{array}{l}\text { Cronología } \\
{ }^{14} \mathrm{C} \text { años AP }\end{array}$ & $\begin{array}{l}N^{\circ} \text { de } \\
\text { muestras }\end{array}$ & $\begin{array}{l}\text { Código de } \\
\text { Laboratorio }\end{array}$ & $\begin{array}{l}\delta^{13} C_{c o l} \\
(\% \circ)\end{array}$ & $\begin{array}{l}\delta^{15} \mathrm{~N} \\
(\% \circ)\end{array}$ & $\mathrm{C} / \mathrm{N}$ & $\begin{array}{l}\text { Material } \\
\text { fechado }\end{array}$ \\
\hline \multirow{27}{*}{ 荧 } & Potrero de Garay ${ }^{1}$ & $31^{\circ} 50^{\prime}$ & $64^{\circ} 30^{\prime}$ & $\mathrm{E} 1 / 58$ & $\mathrm{~F}$ & 39,5 & $383 \pm 58$ & 1 & MTC-14025 & $-13,3$ & 7,5 & 3,2 & diente \\
\hline & Nunsacat $^{1}$ & $30^{\circ} 38^{\prime}$ & $64^{\circ} 29^{\prime}$ & $1 \mathrm{~A}$ & $\mathrm{~F}$ & 33 & $387 \pm 41$ & 3 & --- & --- & --- & --- & --- \\
\hline & Nunsacat $^{1}$ & $30^{\circ} 38^{\prime}$ & $64^{\circ} 29^{\prime}$ & $1 \mathrm{~B}$ & M & 34,5 & $387 \pm 41$ & 4 & MTC-13250 & $-13,4$ & 8,5 & 3,1 & hueso \\
\hline & Potrero de Garay ${ }^{1}$ & $31^{\circ} 50^{\prime}$ & $64^{\circ} 30^{\prime}$ & E9 & M & 20,5 & $420 \pm 41$ & 1 & MTC-13254 & $-17,5$ & 8,2 & 3,3 & hueso \\
\hline & Cañada Larga $^{5}$ & $31^{\circ} 71^{\prime}$ & $65^{\circ} 01^{\prime}$ & $1 \mathrm{~A}$ & M & 24,5 & $481 \pm 57$ & 4 & MTC-14020 & $-16,5$ & 7,7 & 3,2 & diente \\
\hline & \begin{tabular}{|l|} 
Loteo 5-Santa \\
Rosa $^{6}$ \\
\end{tabular} & $32^{\circ} 05^{\prime}$ & $64^{\circ} 32^{\prime}$ & $1 \mathrm{~A}$ & $\mathrm{~F}$ & 37,5 & $533 \pm 42$ & 7 & AA102659 & $-12,7$ & --- & --- & hueso \\
\hline & \begin{tabular}{|l|} 
Loteo 5-Santa \\
Rosa $^{6}$ \\
\end{tabular} & $31^{\circ} 50^{\prime}$ & $64^{\circ} 30^{\prime}$ & $1 \mathrm{~B}$ & $\mathrm{~F}$ & 57 & $533 \pm 42$ & 1 & --- & --- & --- & --- & --- \\
\hline & Ayampitín $^{2}$ & $31^{\circ} 20^{\prime}$ & $64^{\circ} 52^{\prime}$ & $1 \mathrm{~A}$ & M & 29,5 & $600 \pm 20$ & 3 & UCI AMS 22287 & $-12,8$ & 8,2 & 3 & diente \\
\hline & \begin{tabular}{|l|} 
Constantinopla \\
$1215^{6}$ \\
\end{tabular} & $31^{\circ} 40^{\prime}$ & $64^{\circ} 25^{\prime}$ & $1 \mathrm{~A}$ & M & 32 & $619 \pm 43$ & 13 & AA102658 & $-15,4$ & --- & --- & hueso \\
\hline & Copina $^{6}$ & $31^{\circ} 33^{\prime}$ & $64^{\circ} 42^{\prime}$ & $1 \mathrm{~B}$ & M & 37 & $680 \pm 40$ & 8 & MTC-13248 & $-13,6$ & 9,3 & 3,1 & diente \\
\hline & Amboy $^{2}$ & $32^{\circ} 10^{\prime}$ & $64^{\circ} 34^{\prime}$ & $1 \mathrm{~A}$ & M & 42,5 & $830 \pm 20$ & 2 & UCI AMS 22283 & $-13,3$ & 7,7 & 2,9 & diente \\
\hline & Potrero de Garay ${ }^{1}$ & $31^{\circ} 50^{\prime}$ & $64^{\circ} 30^{\prime}$ & $\mathrm{E} 6 / 56$ & $\mathrm{M}$ & 39,5 & $881 \pm 150$ & 13 & MTC-13215 & $-10,5$ & 9,1 & 3 & diente \\
\hline & \begin{tabular}{|l} 
Potrero de Garay ${ }^{6}$ \\
\end{tabular} & $31^{\circ} 50^{\prime}$ & $64^{\circ} 30^{\prime}$ & $\mathrm{E} 4 / 57$ & $\mathrm{~F}$ & $\mathrm{Ad}$ & $889 \pm 59$ & 4 & MTC-14028 & $-11,4$ & 8,5 & 3,2 & diente \\
\hline & Guasmara $^{2}$ & $31^{\circ} 56^{\prime}$ & $65^{\circ} 12^{\prime}$ & $1 \mathrm{~A}$ & M & 22 & $920 \pm 20$ & 7 & --- & --- & --- & --- & --- \\
\hline & Guasmara $^{2}$ & $31^{\circ} 56^{\prime}$ & $65^{\circ} 12^{\prime}$ & $1 \mathrm{~B}$ & M & 21 & $920 \pm 20$ & 9 & UCI AMS 22281 & $-17,7$ & 6,7 & 2,7 & diente \\
\hline & Loma Bola ${ }^{1}$ & $32^{\circ} 13^{\prime}$ & $65^{\circ} 01^{\prime}$ & $1 \mathrm{~A}$ & M & 47,5 & $954 \pm 85$ & 1 & MTC-12806 & $-16,3$ & 9 & 3,2 & diente \\
\hline & Loma Bola ${ }^{1}$ & $32^{\circ} 13^{\prime}$ & $65^{\circ} 01^{\prime}$ & $1 \mathrm{~B}$ & $\mathrm{~F}$ & 42,5 & $954 \pm 85$ & 13 & --- & --- & --- & \begin{tabular}{|c|}
--- \\
\end{tabular} & --- \\
\hline & San Esteban ${ }^{3}$ & $30^{\circ} 95^{\prime}$ & $64^{\circ} 52^{\prime}$ & $1 \mathrm{~A}$ & $\mathrm{~F}$ & 17,5 & $965 \pm 15$ & 2 & UCI AMS 39103 & $-11,3$ & 8,3 & 2,75 & huesos \\
\hline & Potrero de Garay ${ }^{6}$ & $31^{\circ} 50^{\prime}$ & $64^{\circ} 30^{\prime}$ & E3/ 41 & $\mathrm{~F}$ & $\mathrm{Ad}$ & $981 \pm 41$ & 20 & MTC-13251 & $-11,9$ & 9,2 & 3 & diente \\
\hline & Potrero de Garay ${ }^{1}$ & $31^{\circ} 50^{\prime}$ & $64^{\circ} 30^{\prime}$ & $\mathrm{E} 8 / 53$ & M & 34,5 & $995 \pm 161$ & 12 & MTC-13246 & -15 & 8,9 & 3 & diente \\
\hline & Cuesta Blanca $^{1}$ & $31^{\circ} 28^{\prime}$ & $64^{\circ} 34^{\prime}$ & $1 \mathrm{~A}$ & M & AJ & $1080 \pm 40$ & 7 & MTC-13249 & $-13,8$ & 9,2 & 3,1 & diente \\
\hline & Potrero de Garay ${ }^{5}$ & $31^{\circ} 50^{\prime}$ & $64^{\circ} 30^{\prime}$ & $\mathrm{E} 12 / 51$ & M & $\mathrm{Ad}$ & $\mathrm{S} / \mathrm{F}$ & 1 & --- & --- & --- & \begin{tabular}{|l|}
--- \\
\end{tabular} & --- \\
\hline & Paso Cabral ${ }^{5}$ & $32^{\circ} 43^{\prime}$ & $64^{\circ} 48^{\prime}$ & $1 \mathrm{~A}$ & M & $\mathrm{Ad}$ & $\mathrm{S} / \mathrm{F}$ & 1 & --- & --- & -- & --- & --- \\
\hline & La Granja $^{2}$ & $31^{\circ} 02^{\prime}$ & $64^{\circ} 16^{\prime}$ & $1 \mathrm{~A}$ & $\mathrm{~F}$ & 40 & $1280 \pm 15$ & 1 & UCI AMS 22282 & -16 & 9,8 & 2,8 & hueso \\
\hline & Ecoterra $^{4}$ & $31^{\circ} 23^{\prime}$ & $64^{\circ} 32^{\prime}$ & $1 \mathrm{~A}$ & $\mathrm{M}$ & 29 & $1881 \pm 39$ & 24 & AA104742 & $-11,8$ & --- & --- & hueso \\
\hline & El Vado ${ }^{1}$ & $30^{\circ} 51^{\prime}$ & $64^{\circ} 13^{\prime}$ & $1 \mathrm{~A}$ & $\mathrm{~F}$ & 40,5 & $2156 \pm 86$ & 3 & MTC-12808 & --- & --- & --- & hueso \\
\hline & Copina $^{6}$ & $31^{\circ} 33^{\prime}$ & $64^{\circ} 42^{\prime}$ & $1 \mathrm{~A}$ & M & 34,5 & $2707 \pm 61$ & 8 & MTC-14027 & $-16,8$ & 8,3 & 3,3 & diente \\
\hline \multirow{17}{*}{ 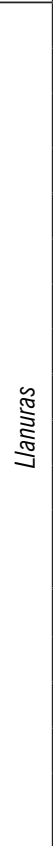 } & El Diquecito $08^{3}$ & $30^{\circ} 53^{\prime}$ & $62^{\circ} 50^{\prime}$ & M1 & $\mathrm{F}$ & 37 & $537 \pm 57$ & 3 & MTC-14022 & $-15,5$ & 8,9 & 3,2 & Hueso \\
\hline & El Diquecito $010^{3}$ & $30^{\circ} 53^{\prime}$ & $62^{\circ} 50^{\prime}$ & $\mathrm{P} 1$ & $\mathrm{~F}$ & 42,5 & $597 \pm 41$ & 8 & AA93744 & $-14,8$ & --- & --- & --- \\
\hline & Laguna de la Sal $^{1}$ & $29^{\circ} 52^{\prime}$ & $63^{\circ} 20^{\prime}$ & $1 \mathrm{~A}$ & M & $\mathrm{Ad}$ & $623 \pm 42$ & 12 & MTC-13255 & $-17,6$ & 11,6 & 3,2 & Diente \\
\hline & La Orihuela ${ }^{3}$ & $30^{\circ} 52^{\prime}$ & $62^{\circ} 28^{\prime}$ & $1 \mathrm{~A}$ & M & 31 & $664 \pm 33$ & 11 & AA104741 & $-14,5$ & --- & --- & Hueso \\
\hline & El Diquecito $08^{1}$ & $30^{\circ} 53^{\prime}$ & $62^{\circ} 50^{\prime}$ & $\mathrm{A} 1$ & $\mathrm{~F}$ & 47 & $698 \pm 42$ & 6 & AA93743 & $-16,2$ & --- & --- & Hueso \\
\hline & El Diquecito $08^{1}$ & $30^{\circ} 53^{\prime}$ & $62^{\circ} 50^{\prime}$ & $\mathrm{B} 1$ & M & 22 & $750 \pm 85$ & 6 & MTC-12807 & $-15,1$ & 10,1 & 3 & Hueso \\
\hline & El Diquecito $08^{5}$ & $30^{\circ} 53^{\prime}$ & $62^{\circ} 50^{\prime}$ & B2 & M & 9 & $750 \pm 85$ & 11 & --- & --- & --- & --- & --- \\
\hline & El Diquecito $08^{1}$ & $30^{\circ} 53^{\prime}$ & $62^{\circ} 50^{\prime}$ & L1 & $M$ & 42,5 & $937 \pm 150$ & 6 & MTC-13214 & $-15,8$ & 9,4 & 3,1 & Hueso \\
\hline & El Diquecito $08^{1}$ & $30^{\circ} 53^{\prime}$ & $62^{\circ} 50^{\prime}$ & E1 & $\mathrm{M}$ & 34,5 & $1192 \pm 40$ & 7 & MTC-13247 & $-14,9$ & 12 & 3,1 & Hueso \\
\hline & Miramar I ${ }^{5}$ & $30^{\circ} 54^{\prime}$ & $62^{\circ} 40^{\prime}$ & $1 \mathrm{~A}$ & $M$ & $\mathrm{Ad}$ & $\mathrm{S} / \mathrm{F}$ & 3 & --- & --- & --- & --- & --- \\
\hline & Laguna del Plata $^{6}$ & $30^{\circ} 54^{\prime}$ & $62^{\circ} 54^{\prime}$ & $1 \mathrm{~A}$ & $M$ & 38,5 & $1241 \pm 57$ & 7 & AA102654 & $-15,6$ & --- & --- & Hueso \\
\hline & \begin{tabular}{|l|} 
Estancia La Elisa \\
$09^{6}$
\end{tabular} & $30^{\circ} 43^{\prime}$ & $62^{\circ} 59^{\prime}$ & $1 \mathrm{~A}$ & M & 44 & $1890 \pm 49$ & 4 & AA102656 & $-16,9$ & --- & --- & Hueso \\
\hline & El Diquecito $08^{1}$ & $30^{\circ} 53^{\prime}$ & $62^{\circ} 50^{\prime}$ & G1 & $\mathrm{F}$ & 39,5 & $1911 \pm 59$ & 9 & MTC-14023 & $-15,4$ & 9,4 & 3,3 & Hueso \\
\hline & El Diquecito $010^{1}$ & $30^{\circ} 53^{\prime}$ & $62^{\circ} 50^{\prime}$ & S1 & $\mathrm{M}$ & 37 & $2331 \pm 46$ & 10 & AA93745 & -14 & -- & --- & Hueso \\
\hline & El Diquecito $010^{3}$ & $30^{\circ} 53^{\prime}$ & $62^{\circ} 50^{\prime}$ & Q1 & $\mathrm{M}$ & 51,5 & $2400 \pm 47$ & 10 & AA93740 & $-18,3$ & --- & \begin{tabular}{|c|}
--- \\
\end{tabular} & Hueso \\
\hline & El Diquecito $010^{3}$ & $30^{\circ} 53^{\prime}$ & $62^{\circ} 50^{\prime}$ & $\mathrm{R} 1$ & $\mathrm{~F}$ & 34 & $2562 \pm 47$ & 4 & AA93742 & $-16,3$ & --- & \begin{tabular}{|l|}
--- \\
-
\end{tabular} & Hueso \\
\hline & \begin{tabular}{|l} 
Estancia La Elisa \\
$12^{2}$
\end{tabular} & $30^{\circ} 43^{\prime}$ & $62^{\circ} 59^{\prime}$ & $1 \mathrm{~A}$ & M & 40,5 & $4058 \pm 89$ & 2 & AA102655 & $-16,5$ & --- & --- & Hueso \\
\hline
\end{tabular}

Tabla 1. Composición de la muestra. F: femenino; M: masculino; S/F: Sin fechado radiocarbónico; Ad.: Adulto; AJ: Adulto Joven; POST: Posterior a 1200 años AP; PRE: Previo a 1200 años AP; MTC: Universidad de Tokio, UCIAMS: Universidad de Irving; AA: Universidad de Arizona. ${ }^{1}$ Fabra y Demarchi (2013), ${ }^{2}$ Laguens et al. (2009), ${ }^{3}$ Fabra et al. $(2009),{ }^{4}$ González y Fabra (2018), ${ }^{5}$ este trabajo, ${ }^{6}$ Fabra y González (2019). 
Para la asociación de los valores isotópicos con un tipo particular de patrón fotosintético, se siguieron las pautas clasificatorias propuestas por Coltrain y Leavitt (2002) y Giardina y colaboradores (2014), quienes sostienen que poblaciones con un consumo relativamente alto de recursos $C_{4}$ presentarán valores promedio cercanos o menores de $\delta^{13} \mathrm{C}$ de $-14 \%$, mientras que aquellas con una dieta principalmente mixta presentarán valores entre -14 y $-17 \%$. Finalmente, poblaciones con dietas ricas en alimentos $\mathrm{C}_{3}$ tendrán promedios por encima de -17\% (Giardina et al., 2014). En relación con los valores de $\delta^{15} \mathrm{~N}$, los autores señalan que la mayoría de las plantas terrestres pueden obtener el nitrógeno a partir de las bacterias $u$ otros organismos presentes en el suelo. Sus valores se encuentran en un rango comprendido entre $2 \%$ y $6 \%$, el cual puede variar según la temperatura y la aridez ambiental (Ambrose, 1991; Pate, 1994). Por otro lado, y debido a que los estudios dietarios que se encuentran basados en análisis de isótopos estables deben estar acompañados por los valores correspondientes de los diversos componentes vegetales y animales presentes en las cadenas tróficas, para la reconstrucción se han comparado los datos obtenidos con información isotópica publicada para regiones aledañas, ya que no se cuenta hasta el momento con información sobre la ecología isotópica de distintos ambientes de la provincia de Córdoba. Se han considerado los valores de flora arqueológica del sector centro-oeste argentino, el cual presenta condiciones climáticas y ambientales similares a las de la provincia de Córdoba (Ehleringer et al., 1997, Gil et al., 2006, 2009, 2010; Martínez et al., 2009). A su vez, no hubo necesidad de controlar el efecto Suess debido a que no se trabajó con material moderno. Las muestras humanas fueron corregidas $-4 \%$ para $\delta^{13} C_{\text {col }}$ y $-3 \%$ o para $\delta^{15} \mathrm{~N}$, siguiendo a DeNiro y Epstein (1981), Schoeninger y DeNiro (1984), Ambrose (1993) y Ambrose y Norr (1993) (Tabla 2).

\begin{tabular}{|c|c|c|c|c|c|}
\hline Flora & $\delta^{13} C_{\text {col }} \%$ & $\delta^{15} \mathrm{~N} \%$ & Lat. & Long. & Referencia \\
\hline Prosopis sp. & $-24,9$ & 11,6 & $33-37^{\circ}$ & $70-67^{\circ}$ & Gil et al. (2006) \\
\hline Prosopis sp. & -21 & 2,1 & $30-40^{\circ}$ & --- & Gil et al. (2010) \\
\hline Prosopis sp. & $-24,9$ & 11,6 & $30-40^{\circ}$ & --- & Gil et al. (2010) \\
\hline Geoffroea decorticans & $-20,8$ & 14 & $30-40^{\circ}$ & --- & Gil et al. (2010) \\
\hline Geoffroea decorticans & $-20,2$ & 14 & $33-37^{\circ}$ & $70-67^{\circ}$ & Gil et al. (2006) \\
\hline Chenopodium sp. & $-27,6$ & 6,9 & $30-40^{\circ}$ & --- & Gil et al. (2010) \\
\hline Schinus polygamus & $-24,4$ & 1,6 & $30-40^{\circ}$ & --- & Gil et al. (2010) \\
\hline Phragmite australis & $-23,6$ & 4,2 & $30-40^{\circ}$ & --- & Gil et al. (2010) \\
\hline Phragmite australis & $-22,4$ & 9,5 & $30-40^{\circ}$ & -- & Gil et al. (2010) \\
\hline Lagenaria & $-25,4$ & 10,4 & $30-40^{\circ}$ & --- & Gil et al. (2010) \\
\hline Phaseolus vulgaris & -24 & 5,5 & $30-40^{\circ}$ & --- & Gil et al. (2008) \\
\hline Zea mays & $-9,6$ & 3,9 & $33-37^{\circ}$ & $70-67^{\circ}$ & Gil et al. (2006) \\
\hline Zea mays & $-9,7$ & 9,6 & $30-40^{\circ}$ & --- & Gil et al. (2010) \\
\hline Zea mays & $-9,1$ & 10,2 & $30-40^{\circ}$ & --- & Gil et al. (2010) \\
\hline Zea mays & $-10,3$ & 9,5 & $30-40^{\circ}$ & -- & Gil et al. (2010) \\
\hline Zea mays & $-9,7$ & 3,4 & $30-40^{\circ}$ & --- & Gil et al. (2010) \\
\hline Zea mays & $-9,6$ & 3,9 & $30-40^{\circ}$ & --- & Gil et al. (2010) \\
\hline Cucurbita maxima & $-23,2$ & 13,1 & $33-37^{\circ}$ & $70-67^{\circ}$ & Gil et al. (2006) \\
\hline Cucurbita maxima & $-26,7$ & 6 & $30-40^{\circ}$ & --- & Gil et al. (2010) \\
\hline Cucurbita maxima & $-24,3$ & 7 & $30-40^{\circ}$ & --- & Gil et al. (2010) \\
\hline Cucurbita maxima & $-24,2$ & 9,8 & $30-40^{\circ}$ & --- & Gil et al. (2010) \\
\hline Cucurbita sp. & $-23,2$ & 13,1 & $30-40^{\circ}$ & --- & Gil et al. (2010) \\
\hline
\end{tabular}

Tabla 2. Datos isotópicos de recursos vegetales potencialmente consumidos. 


\section{Agrupamiento temporal y geográfico de las muestras}

La provincia de Córdoba se encuentra ubicada entre los $30^{\circ}$ y $35^{\circ}$ latitud $S$ y los $62^{\circ}$ y $66^{\circ}$ longitud O en la región austral de las Sierras y noroeste de las Llanuras pampeanas, y abarca tanto las cadenas montañosas de las provincias de Córdoba y San Luis como las Ilanuras orientales y occidentales aledañas (Figura 1) (Iriondo, 1990). Geomorfológicamente, esta zona se puede dividir en dos regiones diferentes: Sierras y Llanuras, las cuales se caracterizan por presentar paisajes contrastantes; en ellas se reconocen las provincias Chaqueña, Espinal y Pampeana, dentro del dominio Chaqueño (Cabrera, 1976).

Para analizar la diversidad temporal de la dieta, los individuos fueron agrupados según su cronología, considerando dos bloques temporales diferentes: a) previo a 1200 años $\mathrm{AP}$ - en adelante PRE 1200- (Holoceno tardío inicial 4000-1200 años AP); y b) posterior a 1200 años AP -en adelante POST 1220- (Holoceno tardío final 1200-300 años AP). Esta línea de corte fue decidida en base a la evidencia aportada desde las investigaciones arqueológicas que sugieren cambios en las estrategias de subsistencia por parte de estas poblaciones alrededor de 1200 años AP, fundamentalmente por la incorporación de la horticultura a pequeña escala, la producción cerámica y un mayor nucleamiento social (Fabra et al., 2012). Por otra parte, la evidencia isotópica, arqueológica y bioantropológica sugiere diferencias entre las poblaciones asentadas en las regiones de Sierras y Llanuras que reflejarían diversas estrategias vinculadas con la alimentación (González y Fabra, 2018) y usos del cuerpo (Salega y Fabra 2017), así como cambios en la composición genética (Fabra y Demarchi, 2013). De allí que se tendrá en cuenta la procedencia geográfica de las muestras para analizar la presencia de microrrestos vegetales, así como los valores isotópicos de carbono y nitrógeno.

\section{RESULTADOS}

\section{Microrrestos vegetales}

\section{Región Sierras}

Se analizó un total de 292 muestras de tártaro dental provenientes de 27 individuos $(17$ masculinos - 10 femeninos) recuperados en 16 sitios arqueológicos. Del número total, cuatro (2 masculinos - 2 femeninos) poseen una antigüedad previa al 1200;

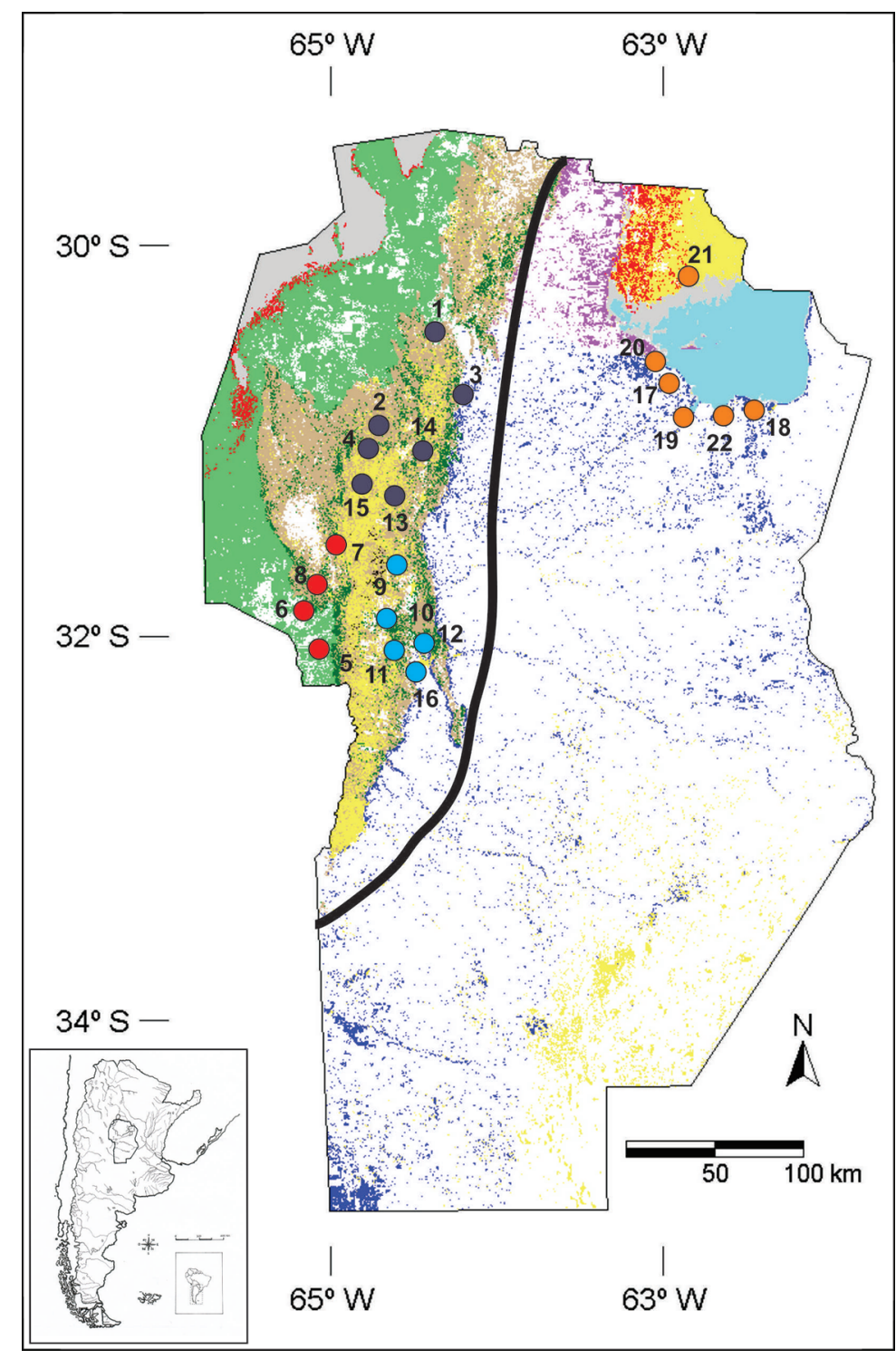

Figura 1. Sitios arqueológicos: Sierras: Valle de Punilla: 1) Nunsacat, 2) San Esteban, 3) El Vado, 4) Ayampitín, 13) Ecoterra, 14) La Granja, 15) Cuesta Blanca; Valle de Traslasierra: 5) Loma Bola, 6) Guasmara, 7) Copina, 8) Cañada Larga; Valle de Calamuchita: 9) Constantinopla 1215, 10) Loteo 5-Santa Rosa, 11) Potrero de Garay, 12) Amboy, 16) Paso Cabral. Llanuras: 17) El Diquecito, 18) La Orihuela, 19) Laguna del Plata, 20) Estancia La Elisa, 21) Laguna de la Sal, 22) Miramar I. Referencia de colores: Verde oscuro: Bosque chaqueño de montaña. Rosado: Matorral chaqueño de montaña. Azul: Bosque del Espinal. Negro: Bosques y matorrales subandinos. Verde claro: Bosque subtropical chaqueño xerófito y matorral. Violeta: Bosque subtropical chaqueño. Rojo: Arbustos halofíticos / subhalofíticos. Blanco: Vegetación cultural. Gris: Depresiones salinas. Turquesa: Agua. Amarillo: Otros. Mapa modificado de Cabido et al. (2018). 
de estos se tomaron 36 muestras de tártaro dental, mientras que de los 23 restantes (15 masculinos 8 femeninos), ubicados en momentos posteriores al 1200, se obtuvieron, en total, 137 muestras de tártaro (Tabla 1$)$.

Los resultados evidenciaron la presencia principalmente de microrrestos vegetales afines a poáceas silvestres, de las cuales se lograron identificar las subfamilias Panicoidea, Danthonioidea, Chloridoidea y Pooidea ( $\mathrm{N}$ total $=2262$ - PRE 1200 $\mathrm{N}=498$, POST $1200 \mathrm{~N}=1764$ ). En las muestras correspondientes al PRE 1200 se observaron 88 elementos silíceos y 63 almidonosos, cuyos atributos morfológicos, según Korstanje y Babot (2007) y Giovannetti et al. (2008), pueden ser asociados a los frutos comestibles del género Prosopis (Fabaceae) "algarrobo"; mientras que en POST 1200 se observaron 241 elementos silíceos y 209 almidonosos asociados al género. A su vez, se hallaron elementos rectangulares de textura plana e incolora ( $\mathrm{N}$ total = 21 - PRE $1200 \mathrm{~N}=17$, POST $1200 \mathrm{~N}=4$ ) que permitieron determinar la presencia de Geoffroea decorticans (Fabaceae) "chañar" en las muestras (Korstanje y Babot, 2007; Medina et al., 2009). Por último, se identificaron, en total, cinco fitolitos esféricos equinados (PRE $1200 \mathrm{~N}=4$, POST 1200 $N=1$ ), los cuales fueron asociados con la familia de las Aracáceas, particularmente con la especie Trithrinax campestris "Palma Caranday" (Benvenuto et al., 2015) (Figura 2).

Con respecto a la presencia de plantas cultivadas, se observaron elementos silíceos y almidonosos en muestras fechadas entre los $1080 \pm 40$ y $387 \pm 41{ }^{14} \mathrm{C}$ años AP, cuyos atributos morfológicos los refieren taxonómicamente al "maíz" Zea mays (Poaceae) (Pearsall et al., 2003; Piperno, 2006), como así también, diez granos de almidón ovalados similares a los citados para el género Phaseolus sp. "poroto" (Babot et al., 2007; Korstanje y Babot, 2007) en los sitios Nunsacat y Loma Bola, con una antigüedad comprendida entre los $387 \pm 41$ y $954 \pm 85{ }^{14} \mathrm{C}$ años AP. En este último sitio, también se identificó un silicofitolito cuyas características morfológicas permitieron asociarlo a la familia de las Cucurbitáceas (Piperno, 2006). Asimismo, se logró la identificación de tres granos almidonosos probablemente afines a la especie Solanum tuberosum "papa" (Korstanje y Babot, 2007), con una antigüedad de $920 \pm 20$ ${ }^{14} \mathrm{C}$ años AP para el sitio Guasmara, y de $680 \pm 40$ ${ }^{14} \mathrm{C}$ años AP para el sitio Copina. Por último, 225 de los elementos encontrados durante el PRE 1200 no pudieron ser asociados a ningún grupo vegetal del que actualmente se tenga referencia, mientras que este número asciende a 505 durante el POST 1200 (Figura 2).

\section{Región Llanura}

En esta región se obtuvo un total de 117 muestras de cálculo dental pertenecientes a 17 individuos (5 femeninos - 12 masculinos) provenientes de seis sitios diferentes. Para momentos previos a 1200 años $\mathrm{AP}$, se recuperaron siete individuos adultos (5 masculinos - 2 femeninos); mientras que para el período correspondiente a POST 1200 años AP se recuperó un total de 10 individuos -nueve adultos (6 masculinos - 3 femeninos) y un juvenil masculino- (Tabla 1).

Para ambos períodos cronológicos, los elementos de afinidad graminoide fueron los más abundantes; entre ellos predominaron las formas elongadas $(\mathrm{N}=569)$ y en cono truncado $(\mathrm{N}=455)$, seguidas por las morfologías en silla de montar $(\mathrm{N}=21)$, bilobadas $(N=66)$, buliformes $(N=67)$ y oblongas $(N=74)$. Particularmente durante el PRE 1200 años AP, se identificó la presencia de elementos rectangulares ( $N=19$ ) afines a Geoffroea decorticans (Fabaceae) "chañar" (Korstanje y Babot, 2007; Medina et al., 2009). A su vez, se documentó el hallazgo de un total de 47 elementos esféricos lisos asociados con los frutos comestibles del género Prosopis (Fabaceae) "algarrobo" (Korstanje y Babot, 2007). Por otro lado, se identificaron tres fitolitos esféricos equinados, asignados a la especie Trithrinax campestris (Arecaceae) "Palma Caranday" (Benvenuto et al., 2015) en los sitios El Diquecito y estancia La Elisa, con antigüedades de $2331 \pm 46$ y $1890 \pm 49{ }^{14} \mathrm{C}$ años AP respectivamente. Con respecto a los granos de almidón, para el período PRE 1200 encontramos una alta abundancia de elementos circulares $(N=67)$, seguida por formas ovales $(N=16) y$, en menor cantidad, poligonales $(\mathrm{N}=3)$. En general, los morfotipos circulares fueron descriptos por Korstanje y Babot (2007) y Giovannetti y colaboradoras (2008) como afines al género Prosopis sp. (Figura 3).

Durante el período POST 1200 se observaron elementos fitolíticos afines a panicoides tales como los morfotipos en forma de cruz $(\mathrm{N}=3)$ y wavy-top rondel $(\mathrm{N}=4)$ en seis individuos con antigüedades comprendidas entre los $1192 \pm 40$ y $537 \pm 57$ ${ }^{14} \mathrm{C}$ años AP. A su vez, se hallaron tres elementos esféricos facetados, lo cual nos permitió identificar 


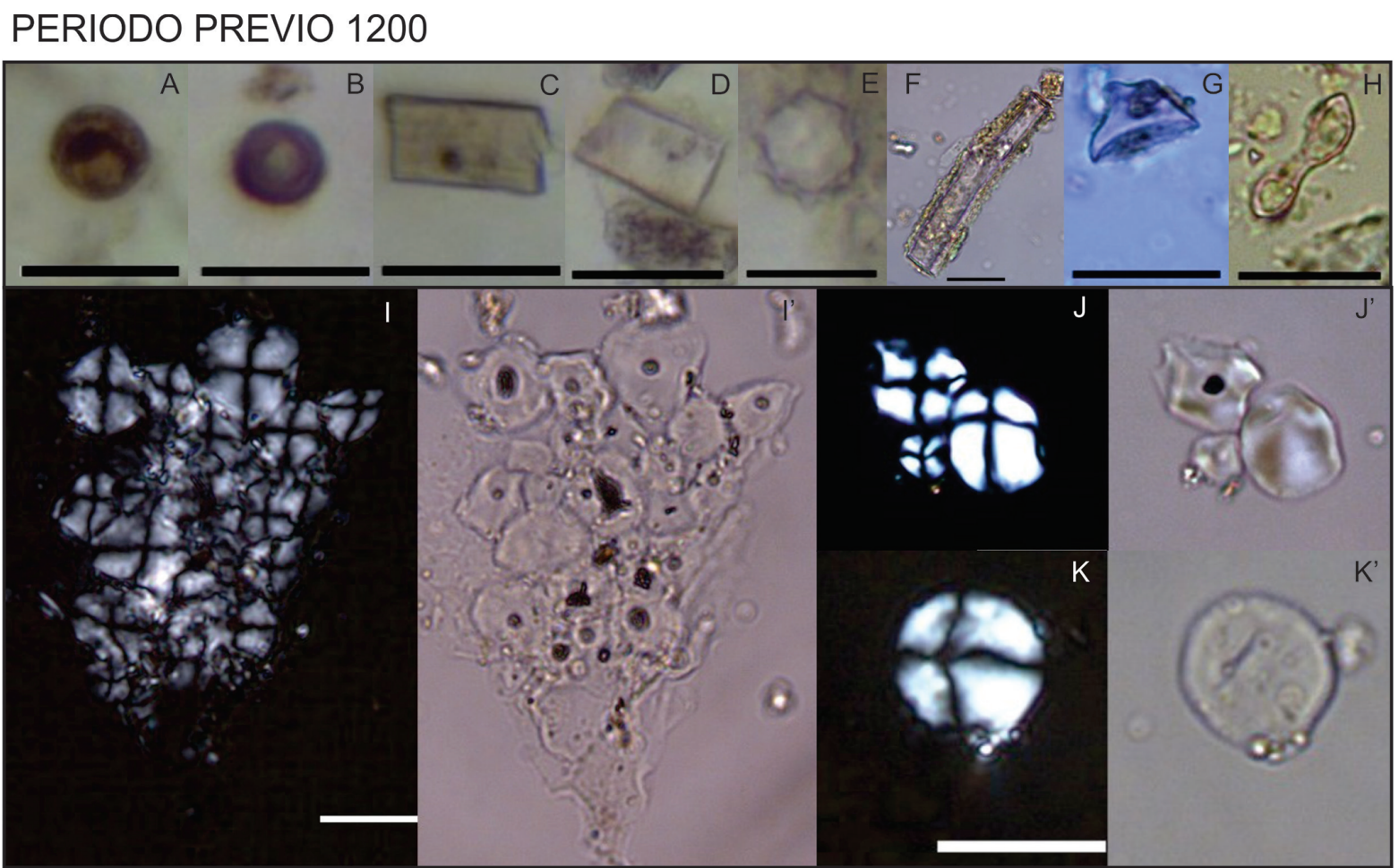

\section{PERIODO POSTERIOR 1200}

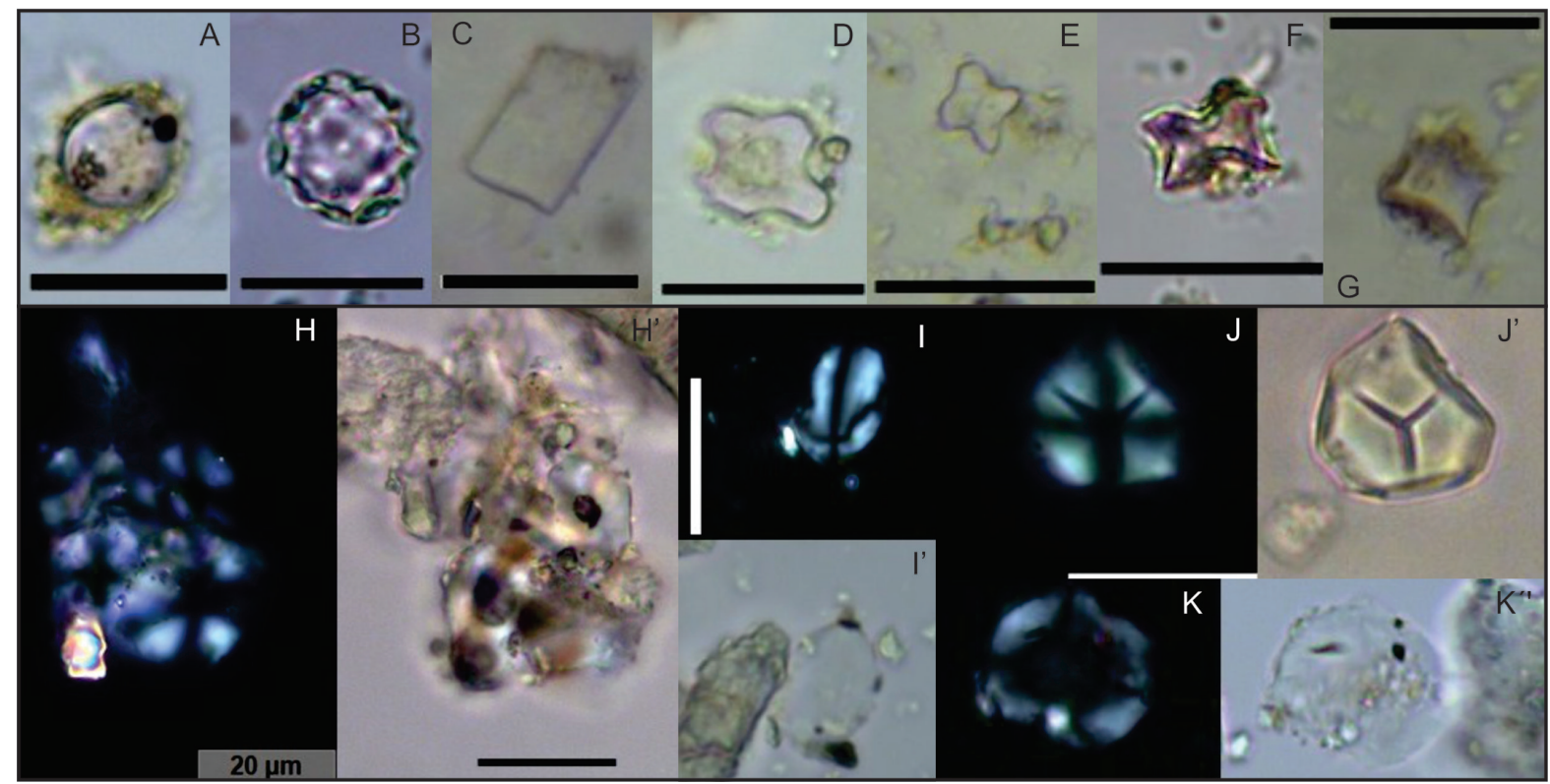

Figura 2. Microrrestos vegetales hallados en la región Sierras. Período previo a 1200 años AP. A-B: silicofitolitos esféricos lisos (spheroid psilate - SPH_PSI). C-D: Morfotipos rectangulares (Medina et al., 2009). E: elemento esférico equinado (spheroid echinate SPH_ECH). F: elemento elongado liso (elongate entire - ELO_ENT). G: Morfotipo en cono truncado (rondel - RON). H: elemento bilobado (bilobate - BIL). I-I', J-J': granos de almidón de morfología circular y poligonal. K-K': grano de almidón circular. Período posterior a 1200 años AP. A: silicofitolito esférico liso (spheroid psilate - SPH_PSI). B: elemento esférico equinado (spheroid echinate - SPH_ECH). C: Morfotipo rectangular (Medina et al., 2009). D-E: elementos en forma de cruz (cross - CRO). F: Morfotipo en cono truncado (rondel - RON). G: Morfotipo wavy-top rondel (Pearsall et al., 2003). H-H': granos de almidón de morfología circular y poligonal. I-l': grano de almidón ovalado. J-J': grano de almidón poligonal. K-K': grano de almidón ovalado. Sinonimia de morfotipos fitolíticos entre paréntesis según ICPN 2.0 (2019). Escala: $20 \mu \mathrm{m}$.

al género Cucurbita sp. en un individuo del sitio El Diquecito con una antigüedad estimada de $937 \pm 150{ }^{14} \mathrm{C}$ años AP (Bozarth, 1987; Piperno y
Stothert, 2003; Piperno, 2006; Medina et al., 2009). Por otro lado, se observó un elemento silíceo esférico equinado afín a la especie Trithrinax campestris 


\section{PERIODO PREVIO 1200}

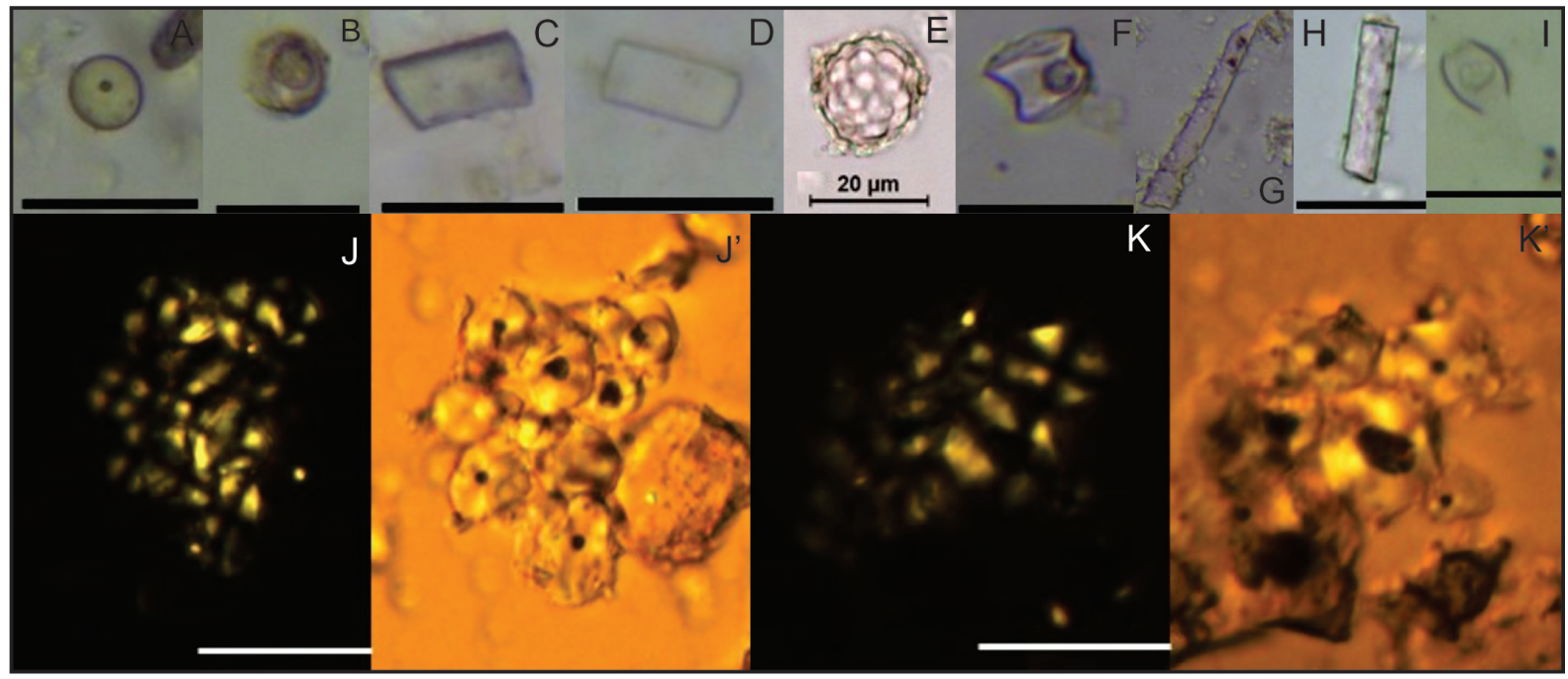

\section{PERIODO POSTERIOR 1200}

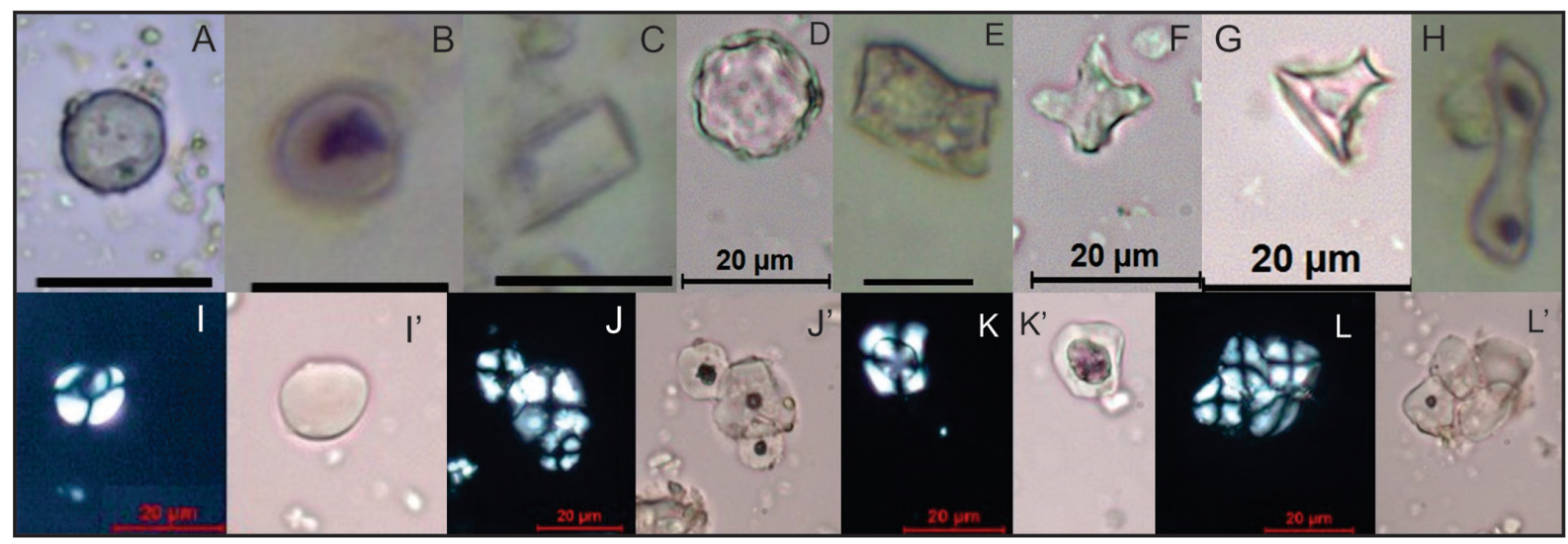

Figura 3. Microrrestos vegetales hallados en la región Llanuras. Período previo a 1200 años AP. A-B: silicofitolitos esféricos lisos (spheroid psilate - SPH_PSI). C-D: Morfotipos rectangulares (Medina et al., 2009). E: elemento esférico equinado (spheroid echinate - SPH_ECH). F: Morfotipo en cono truncado (rondel - RON). G-H: silicofitolito elongado liso (elongate entire - ELO_ENT). I: elemento en forma de silla de montar (saddle - SAD). J-J', K-K': granos de almidón de morfología circular y poligonal. Período posterior a 1200 años AP. A-B: silicofitolitos esféricos lisos (spheroid psilate - SPH_PSI). C: Morfotipo rectangular (Medina et al., 2009). D: silicofitolito esférico facetado (scalloped - Piperno, 2006). E: Morfotipo wavy-top rondel (Pearsall et al., 2003). F: elemento en forma de cruz (cross - CRO). G: Morfotipo en cono truncado (rondel- RON). H: elemento bilobado (bilobate - BIL). I-I': grano de almidón ovalado. J-J': granos de almidón de morfología circular y poligonal. K-K': grano de almidón poligonal. L-L’: granos de almidón de morfología circular y poligonal. Sinonimia de morfotipos fitolíticos entre paréntesis según ICPN 2.0 (2019). Escala: $20 \mu \mathrm{m}$.

(Aracaceae) "Palma Caranday" (Benvenuto et al., 2015) en el sitio Laguna de la Sal, datado en $623 \pm 42{ }^{14} \mathrm{C}$ años AP (Figura 3). Con respecto a los granos de almidón, se hallaron en total 14 elementos cuya morfología coincide con las variedades descriptas para Zea mays "maíz" (Korstanje y Babot, 2007) en seis individuos adultos, cinco provenientes del sitio El Diquecito y uno del sitio La Orihuela, con edades comprendidas entre los $537 \pm 57$ y $1192 \pm 40{ }^{14} \mathrm{C}$ años AP. Además, se observaron cuatro granos ovales arriñonados similares a los citados para Phaseolus sp. "poroto" (Babot et al., 2007; Korstanje y Babot, 2007) en dos individuos del sitio El Diquecito con antigüedades de $1192 \pm 40$ y $537 \pm 57{ }^{14} \mathrm{C}$ años AP respectivamente (Figura 3).

Por otro lado, con respecto a los daños registrados en los microrrestos vegetales hallados en las muestras provenientes de la región central, se observa que los elementos almidonosos fueron los que sufrieron una mayor alteración en sus estructuras originales, las cuales dejan en evidencia que hubo una manipulación de las distintas partes de las plantas a lo largo de todo el periodo analizado.

Del total de granos de almidón $(\mathrm{N}=160)$ hallados en ambas regiones durante el PRE 1200 años 
AP, 91 presentaron modificaciones consistentes con la exposición al calor, manejo y procesamiento de los vegetales; así lo revelan diferentes alteraciones tales como grietas, distorsiones, superficies rotas, cruz de extinción expandida e hinchazón general (Babot, 2003, 2006; Henry y Piperno, 2008; Henry et al., 2009). A su vez, se observaron siete $(N=7)$ silicofitolitos rotos, principalmente bilobados y rectangulares. Particularmente en la región Sierras, de un total de 74 granos de almidón, 23 mostraron las alteraciones previamente mencionadas, mientras que, para en el sector Llanuras, el registro fue de 68 granos de almidón sobre un total de 86 elementos almidonosos.

A su vez, en momentos POST 1200 años AP, si bien se registró la presencia de 285 granos de almidón en la región Sierras y un total de 139 en la región Llanuras, observamos en ambos sectores igual número de elementos afectados por fuentes de calor y la manipulación $(\mathrm{N}=104)$. A su vez, se registró un total de 180 silicofitolitos (12 en la región Sierras y 168 en Llanuras), cuyas superficies originales mostraron roturas compatibles con el procesado o masticado de los vegetales.

\section{Isótopos estables}

Los valores isotópicos obtenidos sobre las muestras óseas y dentales se presentan ordenados considerando las dos grandes regiones de la provincia de Córdoba, Sierras y Llanuras, en la Tabla 1.

\section{Tendencias temporales y espaciales}

Los promedios obtenidos de $\delta^{13} \mathrm{C}_{\mathrm{col}^{\prime}}$ considerando región de origen, presentan valores similares en ambos casos, pero estadísticamente significativos ( $\mathrm{F}=$ $5,868 ; p=0,021)$, siendo $-14,3 \%$ para las Sierras $-\mathrm{n}=21-$ (en un rango entre $-18,1 \%$ y $-10,5 \%$, desvío estándar $=2,324)$ y $-16,2 \%$ en Llanuras $-n$ = 15- (máximo -18,3\%o y mínimo -14\%o, desvío estándar $=1,168$ ). Por otro lado se observa que, para los individuos femeninos, los rangos varían entre $-11,3 \%$ a $-18,1 \%$, con un promedio de $-14,4 \%$ (n $=12$, desvío estándar $=2,224)$. Similares valores se obtienen para individuos masculinos, los cuales presentan un valor mínimo de $-10,5 \%$ y un máximo de $-18,3 \%$, que arroja un promedio de $-15,15 \%$ (n $=24$, desvío estándar $=1,981)$. Estas diferencias entre los sexos no resultan significativas ( $F=1,034$, $p=0,316)$. Por último, durante el período PRE 1200 años AP $(\mathrm{n}=12)$, las muestras presentan valores de $\delta^{13} C_{\text {col }}$ entre $-18,3 \%$ y $-11,8 \%$, con un promedio de $-15,8 \%$ o (desvío estándar $=1,776$ ); esto resulta relativamente más empobrecido que lo registrado para momentos posteriores ( $n=24)$, en que los valores obtenidos presentaron un rango comprendido entre $-17,7 \%$ a $-10,5 \%$, con un valor promedio de $-14,4 \%$ o (desvío estándar $=2,055$ ). Estas diferencias observadas son estadísticamente significativas ( $\mathrm{F}=$ 4,464; $p=0,042)$. Los resultados podrían vincularse con el consumo de una dieta mixta o de amplio espectro, en la cual los recursos vegetales con un patrón fotosintético tipo $\mathrm{C}_{4}$ han tenido una importancia relativa y creciente hacia el Holoceno tardío final, como lo indica también el promedio obtenido para la totalidad de la muestra.

Con respecto a los valores de $\delta^{15} \mathrm{~N}$, los resultados oscilan entre un máximo de $12 \%$ y un mínimo de $6,7 \%$, con un promedio de $8,88 \%$ o para toda la muestra (desvío estándar $=1,196$ ). A su vez, se observan valores promedios más elevados en la región Llanuras $(10,23 \%$, desvío estándar $=1,278$, $\mathrm{n}=6)$ que en Sierras $(8,43 \%$, desvío estándar $=$ $0,777, \mathrm{n}=18$ ), con una diferencia estadísticamente significativa ( $\mathrm{F}=5,070 ; p=0,031)$. Los individuos masculinos presentan valores más elevados de $\delta^{15} \mathrm{~N}$ ( $\mathrm{n}=16$, promedio 8,99\%o, desvío estándar = $1,365)$ que sus pares femeninos $(\mathrm{n}=8$, promedio $8,67 \%$, desvío estándar $=0,796$ ), lo cual podría sugerir una incorporación más alta de proteínas de origen animal en la dieta, pero estas diferencias no resultan estadísticamente significativas $(F=0,018$; $p=0,893)$. En cuanto a las variaciones temporales entre ambos períodos (PRE $1200-\mathrm{n}=5$, promedio 9,46\%o, desvío estándar = 1,633; POST $1200-\mathrm{n}=$ 19, promedio 8,73\%o, desvío estándar $=1,059$ ), los promedios obtenidos resultan levemente más elevados en momentos posteriores, siendo esta diferencia estadísticamente significativa $(F=4,053 ; p=0,05)$.

En la región serrana observamos que, durante el período previo a 1200 años AP, el valor promedio del ${ }^{13} \mathrm{C} /{ }^{12} \mathrm{C}$ resulta más empobrecido que el registrado para ese mismo período en la región Llanuras $(-16,15 \%$ y $-15,7 \%$ respectivamente); mientras que en momentos posteriores a 1200 años AP encontramos una mayor dispersión en el rango de los valores isotópicos $(-17,7 \%$ y $-10,5 \%$, promedio $-14 \%$ ), lo cual podría indicar la incorporación en mayor proporción de plantas con patrón fotosintético de tipo $\mathrm{C}_{4}$ (Figura 4). Por otro lado, en la región Llanuras, los rangos en los valores isotópicos obtenidos para momentos anteriores a 1200 años AP 
resultan similares a los observados para momentos posteriores $(-16,15 \%$ y $-16,05 \%$ respectivamente), esta información podría indicar que el tipo de recurso vegetal no varió significativamente entre ambos momentos, y que la incorporación de plantas $\mathrm{C}_{4^{\prime}}$ tales como el maíz, no constituyó un aporte importante en la dieta (Figura 4).

Considerando el sexo de los individuos, los valores de $\delta^{13} \mathrm{C}$ para momentos posteriores a 1200 años AP indican una dieta más variada en femeninos (promedio -13,8\%o) con respecto a masculinos, probablemente debido a la incorporación de vegetales con patrón fotosintético $\mathrm{C}_{4}$. A su vez, los individuos masculinos presentan valores similares en ambos períodos cronológicos (promedios de $-14,3 \%$ y $-14,1 \%$ respectivamente).

Por otro lado, en la región Llanuras no se observan diferencias que sugieran un cambio o modificación en la selección de los alimentos consumidos por parte de los individuos de ambos sexos a lo largo del tiempo. Por último, podemos observar que los individuos de sexo masculino presentan valores más empobrecidos que sus pares de las Sierras, tanto en momentos previos como posteriores a 1200 años $\mathrm{AP}$, lo cual sugiere un consumo más elevado de plantas con un patrón fotosintético $\mathrm{C}_{3}$.

Si tenemos en cuenta los valores promedio de $\delta^{15} \mathrm{~N}$ durante ambos períodos para hombres $(8,3 \%$
PRE 1200 años AP y 8\% POST 1200 años AP) y mujeres (8,8\% PRE 1200 años AP y 8,65\% POST 1200 años AP) en la región serrana, observamos que son similares, lo que sugiere una alimentación no diferenciada entre los sexos. En la región de Llanura, no se pueden efectuar comparaciones debido a la falta de datos para individuos masculinos en el periodo previo a 1200 años AP. Sí se puede destacar, comparando entre sexos, que para momentos posteriores a 1200 años AP, los valores más elevados se presentan en los individuos masculinos de la región serrana $(10,7 \%)$, lo cual propone un alto aporte cárnico en la dieta.

Los valores de $\delta^{15} \mathrm{~N}$ en la región Sierras se mantienen similares entre ambos períodos. Esto podría sugerir que los individuos de ambos sexos seguían consumiendo alimentos parecidos a lo largo del tiempo; mientras que en la región Llanura, observamos que durante el PRE 1200 años AP los valores se presentan levemente más altos, lo cual indicaría un cambio en la dieta hacia un mayor consumo de proteína de origen animal por parte de los individuos de sexo masculino.

A su vez, se observa que los valores de $\delta^{13} \mathrm{C}$ de la totalidad de las muestras se agrupan entre $-10,5 \%$ y $-18,3 \%$, con un promedio de $-14,4 \%$ y valores de $\delta^{15} \mathrm{~N}$ entre $6,5 \%$ a $12 \%$ y un promedio de $9,35 \%$, lo cual sugiere una variabilidad en cuanto al consumo de recursos con una incorporación relativa

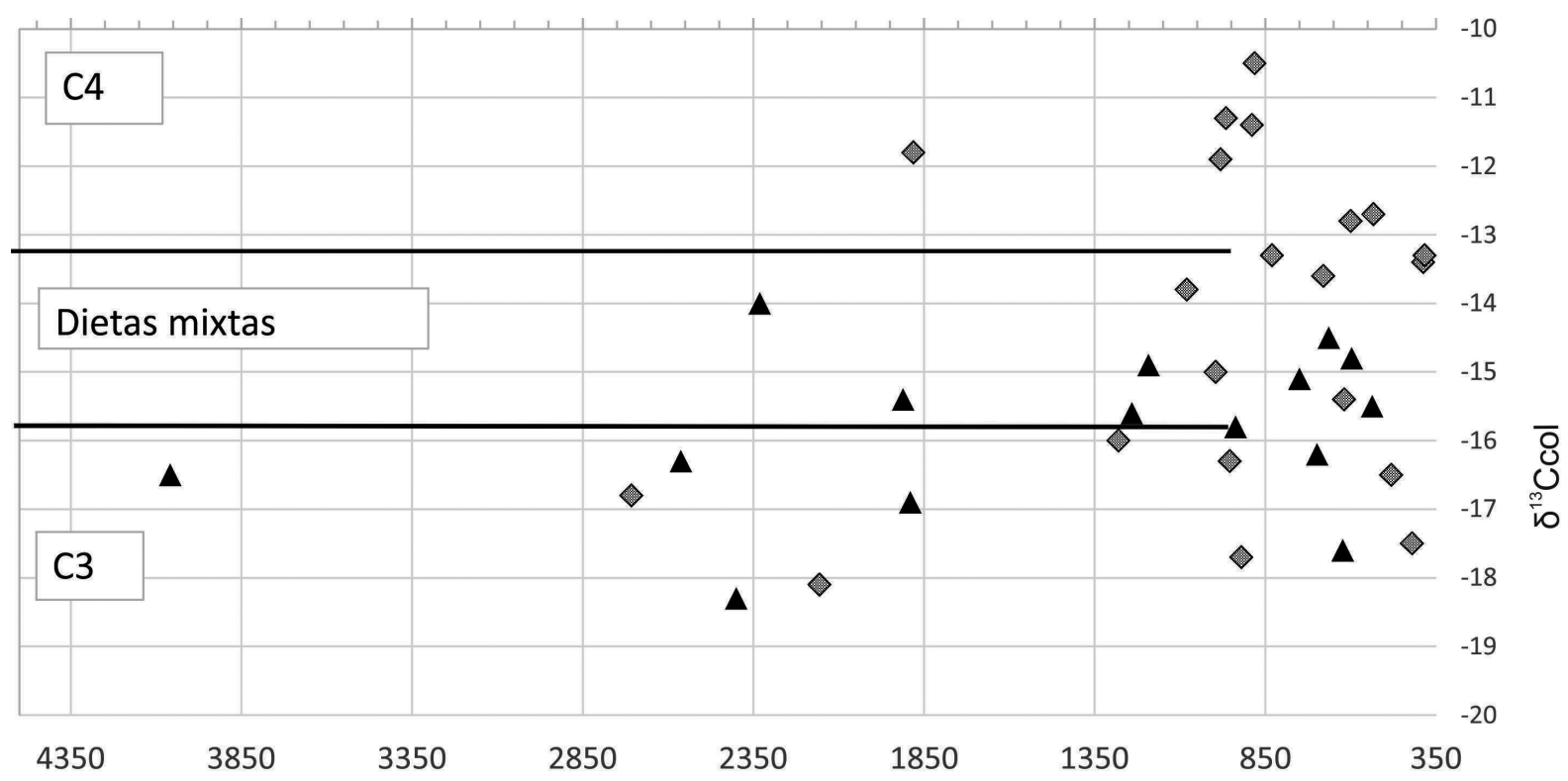

años $14 \mathrm{C}$ AP

Figura 4. Promedios de los valores isotópicos de $\delta^{13} \mathrm{C} \%$ de las muestras óseas según la región y la cronología. Referencias: Triángulos: individuos de Llanuras; Rombos: individuos de Sierras. Líneas continuas: división de valores isotópicos para tipos de dietas (Coltrain y Leavitt, 2002; Giardina et al., 2014). 
de alimentos $\mathrm{C}_{4}$ más marcada para individuos de la región serrana.

La variabilidad observada es más evidente si tenemos en cuenta el origen regional de las muestras: los individuos de las Sierras se acercan más a los recursos del tipo $\mathrm{C}_{4}$ con promedio de $\delta^{13} \mathrm{C}$ de $-14,3 \%$ y valores de $\delta^{15} \mathrm{~N}$ de $8,25 \%$; en cambio, en las Llanuras el promedio de $\delta^{13} \mathrm{C}$ es más empobrecido $\left(-16,15 \%\right.$ ) y el de $\delta^{15} \mathrm{~N}$ es más elevado $(10,45 \%)$. Comparando estos valores isotópicos con los datos de los recursos vegetales, los individuos de las Llanuras se acercan más a valores ofrecidos por los recursos del tipo $\mathrm{C}_{3}$ y con valores de nitrógeno más enriquecidos (Figura 5).

La información aportada desde el análisis de los microrrestos vegetales contenidos en el tártaro dental resulta coincidente con los valores obtenidos para $\delta^{13} \mathrm{C}$ y $\delta^{15} \mathrm{~N}$, los cuales se presentan levemente más enriquecidos a finales del Holoceno tardío, y señalan una incipiente incorporación del maíz en la dieta, principalmente en las mujeres serranas. Es posible que se hayan incorporado otros vegetales con fotosíntesis $\mathrm{C}_{4}$, pero que aún no hemos detectado a partir del estudio de los microrrestos vegetales. Si bien se produjeron hallazgos de elementos silíceos y almidonosos afines al maíz en ambas regiones y para ambos sexos con cronologías posteriores a 1200 años AP, la comparación entre ambas líneas de evidencia nos permite evaluar no solo la presencia de ciertas plantas, sino también la importancia que estas tuvieron en la alimentación de las sociedades prehispánicas.

\section{CONCLUSIÓN}

Los resultados obtenidos a partir del estudio de microrrestos vegetales en el cálculo dental humano, en conjunto con los indicadores bioarqueológicos y la evidencia arqueológica e isotópica (Laguens, 1999; López et al., 2015; Fabra y González, 2019) reflejan el consumo tanto de vegetales silvestres como cultivados durante el Holoceno tardío final. Asimismo, confirman la importancia de las plantas silvestres en la vida de estas sociedades, ya que las prevalencias halladas -principalmente aquellos microrrestos vegetales asociados a los frutos del algarrobo- nos sugieren una continuidad en el consumo a lo largo de todo el Holoceno tardío, práctica que se sostiene hasta la actualidad (Arias Toledo et al., 2007). La baja preponderancia de recursos

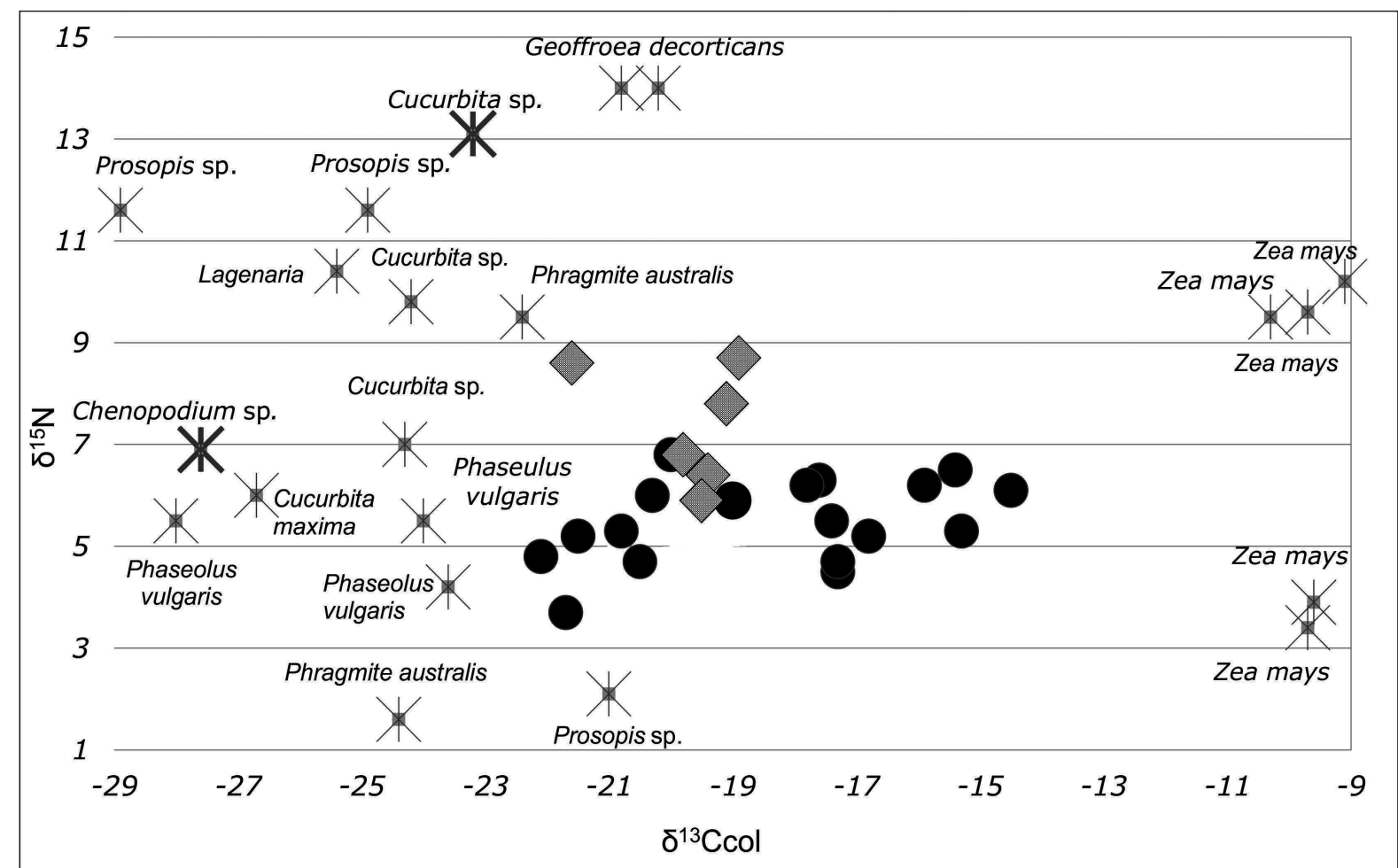

Figura 5. Relaciones isotópicas de $\delta^{13} \mathrm{C}_{\text {col }} \%$ y $\delta^{15} \mathrm{~N}$ de las muestras óseas según la región y los recursos vegetales potencialmente consumibles. Referencias: Rombos: individuos de Llanuras; Círculos: individuos de Sierras; estrella: recursos vegetales; Círculo entrecortado: concentración de individuos de Llanuras; Círculo completo: concentración de individuos de Sierras. Fraccionamiento isotópico corregido en humanos de $-3 \%$ para $\delta^{15} \mathrm{~N}$ y $-4 \%$ para $\delta^{13} \mathrm{C}$ respecto del recurso siguiendo a DeNiro y Epstein (1981), Schoeninger y DeNiro (1984) y Ambrose (1993). 
cultivados con un patrón fotosintético $\mathrm{C}_{4^{\prime}}$ tales como el maíz, en momentos posteriores a 1200 años $\mathrm{AP}$, refuerzan la hipótesis propuesta desde los estudios arqueológicos que plantean un modo de vida basado en una economía mixta.

En este trabajo, los valores de $\delta^{13} \mathrm{C}$ y $\delta^{15} \mathrm{~N}$ obtenidos son coincidentes con lo propuesto por Laguens et al. (2009), Medina et al. (2014) y por Fabra y González (2019), quienes sugieren que la horticultura y particularmente el cultivo del maíz, se habría incorporado de forma parcial a finales del Holoceno tardío y su incidencia no habría sido un fenómeno coetáneo en ambas regiones. Si bien la evidencia obtenida desde los microrrestos vegetales señala una antigüedad similar para los primeros registros de plantas potencialmente cultivadas (ca. 1200 años AP) en ambas regiones, el valor isotópico obtenido por un individuo de la región serrana sugeriría el consumo de plantas con un patrón fotosintético $\mathrm{C}_{4}$ en la región de Sierras en momentos previos.

Considerando la distribución de las plantas silvestres identificadas con mayor frecuencia, observamos que tanto el algarrobo (Prosopis sp.) como el chañar (Geoffroea decorticans) son comúnmente encontrados en toda la provincia, principalmente en el Espinal y Bosque Chaqueño, donde ascienden hasta los 1000 msnm en el caso del algarrobo (Prosopis sp.) y hasta los $1300 \mathrm{msnm}$ en el caso del chañar (Geoffroea decorticans) (Toledo et al., 2015). Por otra parte, la especie endémica Palma Caranday (Trithrinax campestris) suele habitar campos abiertos, pastizales y arbustales del Espinal, Bosque Serrano y Chaqueño, y se la encuentra hasta los 1500 msnm (Toledo et al., 2015). Es interesante destacar que la presencia en el tártaro dental de silicofitolitos afines a dicha especie sugiere un uso relacionado con procesos de manufactura (Pochettino, 2015), el cual indicaría la manipulación con los dientes de sus fibras vegetales extraídas de las hojas, ya que tradicionalmente se usaba en cestería y en la construcción de casas (Correa et al., 2013). En relación con las plantas cultivadas, el maíz y la papa podrían haberse sembrado en todos los pisos ecológicos, a diferencia del poroto común y el zapallo, los cuales no prosperan por encima de los 2000 msnm (Oliszewski y Arreguez, 2015). A partir de esta evidencia, podría pensarse que los grupos humanos que habitaron estos espacios no habrían tenido necesidad de desplazarse grandes distancias para abastecerse de los recursos vegetales más frecuentemente consumidos, ya que estos se encontraban fácilmente en las inmediaciones de los sitios.

A su vez, en la región Llanuras, los asentamientos se habrían dispersado en ambientes relativamente más homogéneos, tanto en las terrazas altas como así también sobre ambos márgenes de los principales cursos de agua, dispuestos en antiguos cauces abandonados del río o bien sobre aquellos que actualmente son considerados temporarios o secundarios, como así también en pequeñas lagunas interiores, que suelen formarse por antiguos brazos o cursos secos del río (Laguens y Bonnin, 2009). La escasa diferencia altitudinal nos indicaría una menor variabilidad climática (Luti et al., 1979), y la localización de los sitios sugiere que las poblaciones asentadas en esta región habrían aprovechado el potencial brindado por la fauna acuática y la vegetación ribereña (Bonofiglio, 2015).

La evidencia obtenida a partir de estas diferentes líneas de investigación sugiere una continuidad de prácticas alimenticias a lo largo del Holoceno tardío, orientadas a una economía mixta en la cual la producción de alimentos cumplió un rol complementario en la dieta, que adquirió mayor dependencia en momentos cercanos a la conquista española.

\section{Agradecimientos}

Las autoras desean agradecer a los siguientes museos públicos que permitieron el acceso a sus colecciones: Museo de Antropología, Museo Capitán Juan de Zevallos, Museo Comechingón, Museo Dr. Dalmacio Vélez Sarsfield, Museo Histórico Municipal de La Para, Museo de la región de Ansenuza Aníbal Montes, al Museo Arqueológico Provincial Aníbal Montes, y a los evaluadores anónimos por sus valiosos aportes, que han mejorado significativamente la calidad del manuscrito. Este trabajo forma parte del proyecto PICT 2015-3155.

\section{REFERENCIAS CITADAS}

Ambrose, S. H. (1991). Effects of diet, climate and physiology on nitrogen isotope abundances in terrestrial foodwebs. Journal of Archaeological Science, 18, 293-317.

Ambrose, S. H. (1993). Isotopic Analysis of Paleodiets: Methodological and Interpretative Considerations. En M. Sanford (ed.), Investigations of Ancient Human Tissue (pp. 59-130). Gordon and Breach Science. 
Ambrose, S. H. y Norr, L. (1993). Experimental Evidence for the Relationship of the Carbon Isotope Ratios of Whole Diet and Dietary Protein to those of Bone Collagen and Carbonate. En J. Lambert y G. Grupe (eds.), Prehistoric Human Bone: Archaeology at the Molecular Level (pp. 1-37). Springer Verlag.

Arias Toledo, B., Colantonio, S. y Galetto, L. (2007). Knowledge and use of edible and medicinal plants in two communities from the Chaco Forest, Córdoba Province, Argentina. Journal of Ethnobiology, 2, 218-232.

Babot, M. P. (2003). Starch grain damage as an indicator of food processing. En D. M. Hart y L. A. Wallis (eds.), Phytolith and starch research in the AustralianPacific-Asian regions: the state of the art (pp. 69-81). Terra Australis 19, Pandanus Books for the Centre for Archaeological Research and the Department of Archaeological and Natural History, The Australian National University.

Babot, M. P. (2006). Damage on starch from processing Andean food plants. En R. Torrence y H. Barton (eds.), Ancient Starch Research (pp. 66- 69). Left Coast Press.

Babot, M. P., Oliszewski, N. y Grau, A. (2007). Análisis de caracteres macroscópicos y microscópicos de Phaseolus vulgaris (Fabaceae, Faboideae) silvestres y cultivados del Noroeste argentino. Una aplicación en arqueobotánica. Darwiniana, 45(2), 149-162.

Benvenuto, M. L., Honaine, M. F., Osterrieth, M. L. y Morel, E. (2015). Differentiation of globular phytoliths in Arecaceae and other monocotyledons: morphological description for paleobotanical application. Turkish Journal of Botany, 39(2), 341-353.

Bonofiglio, M. (2015). Sociedades Lacustres tardías. En A. M. Rocchietti (coord.), X Jornadas de Investigadores en Arqueología y Etnohistoria del Centro Oeste del país (pp. 252-266). Río Cuarto, Córdoba, Argentina.

Bozarth, S.R. (1987). Diagnostic opal phytoliths from rinds of selected Cucurbita species. American Antiquity, 52(3), 607-615.

Cabido, M., Zeballos, S. R., Zak, M., Carranza, M. L., Giorgis, M. A., Cantero, J. J. y Acosta, A. T. (2018). Native woody vegetation in central Argentina: Classification of Chaco and Espinal forests. Applied Vegetation Science, 21, 298-311.

Cabrera, A. L. (1976). Regiones fitogeográficas argentinas. Buenos Aires: Acme.

Coltrain, J. y Leavitt, S. (2002). Climate and Diet in Fremont Prehistory: Economic Variability and Abandonment of Maize Agriculture in the Great Salt Lake Basin. American Antiquity, 67, 453-485.
Correa, A., Toledo, J. y Calandri, E. (Agosto de 2013). Estudio químico de los frutos de la "Palma Caranday" (Trithrinax campestris) y su posible uso como recurso alimenticio. III Congreso de alimentos en el Siglo XXI, Mendoza.

Costa Angrizani, R., Colobig, M. M. y Zucol, A. F. (2019). Identificación de microrrestos botánicos en vasijas guaraníes de la cuenca del río Paraná (Argentina). Arqueología, 25(3), 37-57.

DeNiro, M. y Epstein, S. (1981). Influence of Diet on the Distribution of Nitrogen Isotopes in Animals. Geochimica et Cosmochimica Acta, 45(3), 341-351.

Ehleringer, J. R., Cerling, T. E. y Helliker, B. R. (1997). $\mathrm{C} 4$ photosynthesis, atmospheric $\mathrm{CO} 2$, and climate. Oecologia, 112, 285-299.

Fabra, M. y Demarchi, D. (2013). Análisis morfogeométrico aplicado al estudio de los patrones espaciales y temporales de variación morfológica craneofacial en poblaciones del centro de Argentina. Cuadernos del Instituto Nacional de Pensamiento Latinoamericano, 1(1), 87-101.

Fabra, M. y González, C. V. (2019). Oral health, diet and social change in populations of the region of central Argentina during Late Holocene: Bioarchaeological and isotopic evidence. Latin American Antiquity, 30(4), 818-835.

Giardina, M., Corbat, M., Otaola, C., Salgán, L., Ugan, A., Neme, G. y Gil, A. (2014). Recursos y dietas humanas en Laguna Llancanelo (Mendoza; Nordpatagonia): una discusión isotópica del registro arqueológico. Magallania, 42(1), 111-131.

Gil, A., Tykot, R., Neme, G. y Shelnut, N. (2006). Maize on the Frontier. Isotopic and Macrobotanical Data from Central West Argentina. En J. Staller y R. Tykoy (eds.), Histories of Maize (pp. 199-214). Academic Press.

Gil, A., Neme, G., Hernández, A., Novellino, P., Giardina, M., Salgán, L., Tuker, H. y Albarrán, E. (2009). Rincón del Atuel-1 (San Rafael, Mendoza): evidencias arqueológicas e implicancias regionales. Intersecciones en Antropología, 9, 113-132.

Gil, A., Neme, G. y Tykot, R. (2010). Isótopos estables y consumo de maíz en el centro occidente argentino: tendencias temporales y espaciales. Chungara, Revista de Antropología Chilena, 42(2), 497-513.

Giovannetti, M. A., Lema, V. S., Bartoli, C. G. y Capparelli, A. (2008). Starch grain characterization of Prosopis chilensis (Mol.) Stuntz and P. flexuosa DC, and the analysis of their archaeological remains in Andean South America. Journal of Archaeological Science, 35, 2973-2985. 
González, C. V. y Fabra, M. (2018). Desgaste dental y hábitos dietarios en poblaciones arqueológicas del centro de Argentina. Arqueología, 24(2), 133-159.

Henry, A. y Piperno, D. (2008). Using plant microfossils from dental calculus to recover human diet: A case study from Tell al-Raqa'i, Syria. Journal of Archaeological Science, 35, 1943-1950.

Henry, A., Hudson, H. F. y Piperno, D. (2009). Changes in starch grain morphologies from cooking. Journal of Archaeological Science, 36, 915-922.

ICPN 2.0. (2019). Neumann, K., Strömberg, C., Ball, T., Albert, R., Vrydaghs, L y Scott Cummings, L. International Code for Phytolith Nomenclature. Annals of Botany, XX, 1-11.

ICSN (2011). The International Code for Starch Nomenclature. Consultado el 19 de febrero de 2020. http://www.fossilfarm.org/ICSN/Code.html

Iriondo, M. H., (1990). Map of the South America Plains. Its present state. En J. Rabassa (ed.), Quaternary of South America and Antarctic Peninsula 6 (pp. 297-308). A. A. Balkema.

Korstanje, M. A. y Babot, M. P. (2007). A microfossil characterization from South Andean economic plants. En M. Madella, M. K. Jones y D. Zurro (eds.). Places, People and Plants: Using Phytoliths in Archaeology and Paleoecology (pp. 41-72). Cambridge: Oxbow Books.

Laguens, A. (1999). Arqueología del contacto hispanoindigena. Un estudio de cambios y continuidades en las Sierras Centrales de Argentina. BAR International Series 801. Archaeopress.

Laguens, A., Fabra, M., Dos Santos, G. y Demarchi, D. (2009). Paleodietary inferences based on isotopic evidences for populations of the Central Mountains of Argentina during the Holocene. International Journal of Osteoarchaeology, 19, 237-249.

Laguens, A. y Bonnin, M. (2009). Sociedades indígenas de las Sierras Centrales. Arqueología de Córdoba y San Luis. Universidad Nacional de Córdoba.

Lee-Thorp, J. A. (2008). On isotopes and old bones. Archaeometry, 50(6), 925-950.

López, M. L. (2017). Archaeobotany in central Argentina: macro- and microscopic remains at several archaeological sites from early Late Holocene to early colonial times (3,000-250 bp). Vegetation History and Archaeobotany, 27, 219-228.

López, M. L., Medina, M. y Rivero, D. (2015). First records of Chenopodium spp./Amaranthus spp. starch grains and their relevance to the study of the Late Holocene human subsistence in Central Argentina. Holocene, 25, 288-295.
Luti, R., Solis, M., Galera, F., De Ferreyra, N. M., Berzal, M., Nores, M., Herrera, M. y Barrera, J. (1979). Vegetación. En J. Vázquez, R. Miatello y E. Roqué (eds.), Geografía Física de la Provincia de Córdoba (pp. 297-367). Boldt.

Makarewicz, C. A. y Sealy, J. (2015). Dietary reconstruction, mobility, and the analysis of ancient skeletal tissues: expanding the prospects of stable isotope research in archaeology. Journal of Archaeological Science, 56, 146-158.

Martínez, G., Zangrando, A. y Prates, L. (2009). Isotopic ecology and human paleodiets in the lower basin of the Colorado River, Buenos Aires province, Argentina. International Journal of Osteoarchaeology, 19, 281-296.

Medina, M., López, L. y Berberián, E. (2009). Agricultura y recolección en el Tardío Prehispánico de las Sierras de Córdoba (Argentina): el registro arqueobotánico de C.Pun.39. Arqueología, 15, 217-230.

Medina, M., Pastor, S. y Berberián, E. (2014). "Es Gente Fazil de Moverse de una Parte a Otra". Diversidad en las Estrategias de Subsistencia y Movilidad Prehispánicas Tardías (Sierras de Córdoba, Argentina). Complutum, 25(1), 73-88.

Medina, M., Pastor, S. y Recalde, A. (2016). The archaeological landscape of Late Prehispanic mixed foraging and cultivation economy (Sierras of Cordoba, Argentina). Journal Anthropology Archaeology, 42, 88-104.

Oliszewski, N. y Arreguez, G. (2015). Manejo de recursos vegetales alimenticios en la quebrada de los Corrales, El Infiernillo, Tucumán (2100-1550 años AP). Comechingonia. Revista de Arqueología, 19(2), 111-140.

Pastor, S., López, M. L. y Rivero, D. (2012-2014). Access to maize (Zea mays) and its manipulation in huntergatherer context in central Argentina (ca. 3000-2500 BP). Before Farming, 4, 1-10.

Pate, F. D. (1994). Bone chemistry and paleodiet. Journal of Archaeological Method and Theory, 1, 161-209.

Pearsall, D., Chandler-Ezell, K. y Chandler-Ezell, A. (2003). Identifying maize in neotropical sediments and soils using cob phytoliths. Journal of Archaeological Science, 30(5), 611-627.

Piovano, L. E., Ariztegui, D., Córdoba, F., Cioccale, M. y Sylvestre, F. (2009). Microrrestos de vegetales cultivados y silvestres en fragmentos cerámicos. Primeras evidencias en el Centro Occidente argentino. Arqueología, 25(1) 221-231.

Piperno, D. (2006). Phytoliths. A Comprehensive Guide for Archaeologist and Paleoecologist. Altamira Press. 
Estudio de dieta en poblaciones arqueológicas del centro de Argentina a través del análisis de... Intersecciones en Antropología 21(2), julio-diciembre. 2020. ISSN-e 1850-373X

Piperno, D. y Stothert, K. E. (2003). Phytolith evidence for Early Holocene Cucurbita domestication in Southwest Ecuador. Science, 299, 1054-1057.

Pochettino, M. L. (2015). Botánica económica: las plantas interpretadas según tiempo, espacio y cultura. Sociedad Argentina de Botánica.

Prieto-Olavarría, C., Chiavazza, H. y Musaubach, G. (2019). Microrrestos de vegetales cultivados y silvestres en fragmentos cerámicos. Primeras evidencias en el Centro Occidente argentino. Arqueología, 25(1), 221-231.

Recalde, A. y López, M. L. (2017). Las Sociedades Prehispánicas Tardías en la Región Septentrional del Centro de Argentina (Sierras del Norte, Córdoba). Avances a su Conocimiento desde los Recursos Vegetales. Chungara, Revista de Antropología Chilena, 49, 1-16.

Salega, S. y Fabra, M. (2017). Variaciones del terreno y cambios entesiales en poblaciones prehispánicas de Córdoba (Argentina). Revista del Museo de Antropología, Dossier Marcadores óseos de ¿actividad?: Aproximaciones y limitaciones desde estudios bioarqueológicos, 10(2), 131-136.
Schoeninger, M. y DeNiro, M. (1984). Nitrogen and Carbon Isotopic Composition of Bone Collagen from Marine and Terrestrial Animals. Geochimica et Cosmochimica Acta, 48, 625-639.

Silva, L., Giorgis, M., Anand, M., Enrico, L., PérezHarguindeguy, N., Falczuk, V., Tieszen, L. y Cabido, M. (2011). Evidence of shift in C4 species range in central Argentina during the late Holocene. Plant Soil, 349, 261-279.

Tavarone, A., Colobig, M. M., Passeggi, E. y Fabra, M. (2018). Cleaning protocol of archaeological dental calculus: A methodological proposal for vegetable microremains analysis. American Journal of Physical Anthropology, 167, 416-422.

Tavarone, A., Colobig, M. y Fabra, M. (2019). Late Holocene plant use in lowland central Argentina: Microfossil evidence from dental calculus. Journal of Archaeological Science: report. Reports, 26, 1-12.

Toledo, J. M., Correa, A. y Beltramone, G. (2015). Frutos comestibles nativos de la provincia de Córdoba, Argentina. Advocatus; Universidad Blas Pascal. 
